\title{
Learning Experience in Computer-Based Pronunciation Package
}

\author{
Kretsai Woottipong \\ Faculty of Humanities and Social Sciences, Thaksin University \\ Muang District, Songkhla Province, Thailand \\ E-mail:kretsai@gmail.com
}

Received: July 31, 2015 Accepted: August 18 24, 2015 Published: August 18, 2015

doi:10.5296/jse.v5i3.8080ＵRL:http://dx.doi.org/10.5296/jse.v5i3.8080

\begin{abstract}
The purposes of this study were 1) to evaluate the efficiency of the computer-based pronunciation package for enhancing English pronunciation of Thai university students in the field of sciences based on the criteria of 80/80 Standard 2) to compare English pronunciation ability before and after receiving English pronunciation treatment by the computer-based pronunciation package, and 3) to examine the students' opinion towards the computer-based pronunciation package for enhancing English pronunciation. The sample of the student population for this study was 72 first-year students in the field of sciences in the second semester of the academic year 2013 at Thaksin University, Thailand. They were selected by simple random sampling. The study was conducted over 34 teaching periods. Regarding the data analysis, mean, percentage and t-test scores were employed. The result indicated that 1) the efficiency value of the computer-based pronunciation lessons was 81.88/82.66. 2) The learning achievement on English pronunciation among students using the computer-based pronunciation package was higher than those taught through the conventional face-to-face instruction at a significance level of 0.05. 3) Students had very good attitudes towards learning English pronunciation via the computer-based pronunciation package with an average score of 4.00 .
\end{abstract}

keywords: Computer-based pronunciation package, Learning experience 


\section{Introduction}

\subsection{Rationale for the Study}

Pronunciation is a crucial element of the learning of oral skills in second and foreign languages. English, both written and spoken, has been recognized as the dominant means of successful communication for most of the world (Yong, 2004). Pronunciation plays a key role in helping the learner become an intelligible speaker (Morley, 1998). The ability to speak in a standard way would also be beneficial for foreign learner of English (Jones, 1988) because good pronunciation may make the communication easier and more useful whereas too much accented or distorted speech can frequently lead to misunderstandings, miscommunication and frustration ( $\mathrm{Lu}, 2002)$.

However, the obstacles in improving Thai students' pronunciation of English have long existed and many methods of English language teaching employed in Thailand tend to neglect the teaching of pronunciation. According to Romwapee (2013), it seems that teaching pronunciation is insufficient for Thai students. Wei and Zhou (2002) also stated that teaching English pronunciation seems to be overlooked in some university curricular in Thailand.

In addition there are many obstacles for Thai teachers to teach English such as the teacher's insufficient knowledge of pronunciation and time restriction (Biyaem, 1997 and Lin, et al, 1995). It might be because English pronunciation is one of the most difficult areas for both teachers and students (Jukpim, 2009 as cited in Imamesup, 2011). Kelly (2004) further supports that many experienced teachers would admit a lack of knowledge of the theory of pronunciation teaching and they may therefore feel the need to improve their practical skills in pronunciation teaching. Wei and Zhou (2002) also state that foreign teachers did not know how to teach pronunciation, even if they wanted to teach it. Foreign teachers often lack confidence to teach it methodically. In addition, applied phonetics is barely taught at university, and therefore seems an alien, abstract subject to the adult trainee teacher.

For time restriction, class time spent on pronunciation practice is limited. Practice is important for pronunciation development because students gain more confidence and become more fluent in expressing themselves. However, in a university curriculum, speaking skill constitutes only one of many objectives for learning English. This time is shared between writing, reading, speaking and listening instruction, with only 10 percent of the time allocated to developing speaking skill. The teacher usually spends only 5-10 minutes teaching pronunciation in a traditional classroom. It is not enough for the students to get familiar with their English pronunciation. And, most students have little further opportunity to practice speaking in English outside of the classroom. This view is supported by Wei and Zhou (2002) who explain that most of Thai university students have pronunciation problems due to the limitation of time and lacking of visible targets, most students have neglected it (Wei \& Zhou, 2002 p. 11.)

In addition, although studies on foreign accents within English as a second and foreign language are fascinating for some researchers, the studies in the area of English pronunciation performance of Thai science learners seem to be less examined (Khamkhien, 2010). Thus, 
this study aimed to gain an understanding of the effects of using computer-based pronunciation package in the development of English pronunciation skill for students in the field of sciences.

With computer-assisted instruction, it can be designed to help students practice the pronunciation and teachers can use it to construct an English pronunciation course that solves the problems of class time limitation in a large class. Students can access the internet at home or a university computer center. Research results supported the above statement that computer-assisted instruction (CAI) programs have important factors that can motivate, challenge, enhance curiosity of learners (Tzeng, 1999 as cited in Saffarian and Gorjian, 2012). The design of CALL lessons generally involves principles of language pedagogy that can be taken from learning theories and second language learning. CALL may be described as an approach to teaching and learning foreign languages while the computer and computer-based resources are employed to present, reinforce and evaluate material to be learned.

\subsection{The Purposes of the Study}

The purposes of the study were as follows:

1) To evaluate the efficiency of the computer-based pronunciation package for enhancing English pronunciation of Thai university students in the field of sciences based on the criteria of 80/80 Standard.

2) To compare English pronunciation ability before and after receiving English pronunciation treatment by the computer-based pronunciation package.

3) To examine the students' opinion towards the computer-based pronunciation package for enhancing English pronunciation.

\section{Review of Literature}

\subsection{Pronunciation teaching techniques}

Celce-Murcia et al. (1996 as cited in Imamesup, 2011) state that there are two main approaches to teach pronunciation: an intuitive-imitative approach and an analytic-linguistic approach. An intuitive-imitative approach allows learners to listen and imitate the rhythms and sounds of the target language without the intervention of any explicit instruction whereas an analytic-linguistic approach focuses on utilizing information and tools such as phonetic alphabets and articulatory description to enhance learners' ability in listening, imitation, and production. There are many kinds of techniques and materials that teachers can employ to teach pronunciation (Celce-Murcia et al., 1996 as cited in Imamesup, 2011). The techniques below have been included in the computer-based pronunciation package:

Listen and imitate : The teachers provides models of sounds and students have to repeat or imitate their teachers.

Phonetic training: With this technique, students have to learn how to pronounce by studying the phonetic alphabets, articulatory diagrams and articulatory descriptions. They also have to read the phonetically transcribed text. 
Minimal pair drills : This technique has been used to help students to distinguish between two similar problematic sounds by listening to discrimination and speaking practice. This technique usually begins with word-level drills, then moves on to sentence-level drills.

Visual aids : The teacher uses audiovisual aids such as sound-color charts, pictures, rods to describe how the sounds are produced. This technique is usually used in the state of production.

\subsection{Factors influencing pronunciation}

According to Shoebottom (2012 as cited in Mikuláštíková), some of the factors can influence acquiring pronunciation skills prosperously while some of them are far beyond human control. These factors can be classified into internal and external groups. For internal factors, they consist of age, personality, motivation, experiences, cognition and native language. The factors are incorporated into student's individual language.

Age: It is proved that children are the most talented ones in terms of acquiring EFL. However, adults can achieve a reasonable progress in obtaining pronunciation skills successfully if they are well motivated and determined.

Personality: Students who are of introvert character are usually afraid of expressing themselves orally; they do not rather look for any opportunities to speak. On the other hand, extrovert students are usually seeking for taking part in every conversation, ignoring their mistakes.

Motivation: It is important to distinguish between intrinsic and extrinsic motivation. Students who are intrinsically motivated exhibit greater interest and enjoyment in their English language development. Students who need to study English in order to take a better job or to communicate with relatives who live in an English speaking country (so they are extrinsically motivated) are also likely to achieve better results.

Experiences: Students who have already been exposed to some foreign language have greater chances to acquire a new language easier than students who have never encountered one.

Cognition: It is believed by some linguists that the cognitive abilities that are stronger with some students than with some others can lead to faster language progress.

Native language: Students who try to acquire a foreign language which belongs to the same language family as their native language have greater chance than those students who try to master a language from a family group that is different from their native tongue.

For external factors, they include curriculum, instruction, culture and status, motivation and access to native speakers. The factors characterize the particular language learning situation (Shoebottom, 2012 as cited in Mikuláštíková).

Curriculum: It is important to expose students of ESL to such a workload which is appropriate for their studying needs.

Instruction: It depends also on teacher's teaching skills and abilities how successful students 
are in terms of their language development. In addition to this, students who are exposed to some ELT also in other subjects reach greater progress.

Culture and Status: It has been noticed that students whose culture possesses a lower status than the culture whose language they are exposed to achieve the language skills slower.

Motivation: It is proved that students who are continually supported to better their language skills by their families or teachers reach a greater success.

Access to native speakers: Students who have the possibility to meet with native speakers lose the fears to communicate. Native speakers provide a linguistic model and an appropriate feedback for students.

\subsection{The Use of Computers in Language Learning}

CALL is an emerging force in language education. Despite the on-going resistance of many in the field of language teaching, it is maturing and showing that it can be a powerful tool in the hands of experienced teachers (Knowles, 2004 as cited in Yiğit, 2013). Hazari and Schnorr (1999) stated that this new development in CALL benefits students- learning environment by helping them increase their understanding where other methods have had limited success. This is because this tool supports the constructivist theory which is the development of learners- capacity for goal setting, self-planning and self-monitoring where they are able to assimilate knowledge at their own learning pace.

According to Salomon (1988), the use of hypermedia may not only be helpful in terms of enhancing deeper learning by encouraging learners to think about how new information is related to existing knowledge, but it may be an alternative tool to the extent that it provides a cluster of learning modes such as text, audio, graphics, and synchronous and asynchronous communication that can be made to suit individual learning styles. This is in line with Spiro and Jehng (1990) who mentioned that computer-assisted instruction is a non-linear teaching medium that may encourage deeper processing and cognitive flexibility in learners. Hypermedia is organized in a non-linear format and uses several types of media such as audio, video, and text which encourage learners to access reference materials based on their individual needs (Tessmer, 1993).

Erricolo and Matthes (2008) noted that computer-assisted instruction is useful for learners who cannot attend classrooms due to their limitations in terms of financial resources, professional commitments or physical constraints. Learners can access the teaching materials anytime or anywhere. For teachers, the teaching materials can be modified or kept up to date easily. Visual images are very important for some courses and this tool offers clarity in the explanation of things to learners. In addition, Chute, Thompson and Hancock (1999) supported the notion that this tool is beneficial in that it readily accommodates individual differences and self-paced learning. Computer-assisted instruction is highly beneficial for the learning dynamics of students with different learning styles.

\section{Methodology}

\subsection{Population and Sample}

The population consisted of 192 students who enrolled in General English II in the second 
semester of the academic year 2013 at Thaksin University, Thailand. The group of students was purposively selected from 2 faculties that are Faculty of Sciences and Faculty of Education within the area of sciences. They were classified as medium and low EFL students based on their pre-test scores. They had either knowledge of English pronunciation as indicated by the result of their answers to pronunciation knowledge interview conducted by the researcher before the implementation of the sample selection process.

Table 1. Number of participants in the experiment and control groups

\begin{tabular}{|c|c|c|c|c|}
\hline Proficiency & Experiment & Control & Total & Percentage \\
\hline Medium & 14 & 15 & 29 & 40 \\
\hline Low & 21 & 22 & 43 & 60 \\
\hline Total & 35 & 37 & 72 & 100 \\
\hline
\end{tabular}

Out of the 72 participants, 29 participants (40\%) were identified as medium proficiency participants, whereas 43 participants $(60 \%)$ as low proficiency participants. Thirty-five participants (14 medium and 21 low) were randomly assigned to the experimental group. The control group consisted of 37 participants (15 medium, and 22 low). Table 1 above summarizes the number of the participants in the experiment and the control groups based on their proficiency levels.

The following steps were used to select the participants:

1. The students in General English II classes were approached and asked whether they would be willing to participate in the study by giving out a consent form for each of them to fill out.

2. The students who consented to participate in the study filled out consent form. Each consented student about the knowledge of English pronunciation. It appeared that most of them either did not know or knew very little about the English pronunciation, hence being counted as possessing no knowledge of text structures strategy.

3. They then took a pre-test which consisted of 40 multiple-choice items and lasted 1 hour.

4. The thirty-two students (with at least $\mathrm{B}+$ grades in their previous English exam) who gained higher than 30 out of the total 40 scores were excluded from the study because they were regarded as high proficiency learners, who were not the target group of this study.

5. Finally, 72 students, 16 male $(22.22 \%)$ and 56 female $(77.77 \%)$, were selected for the present study.

The participants were selected for this study based on the following reasons: First, they were attending General English II Course at the time of the experiment. Secondly, they had limited or no knowledge about English pronunciation, as identified by the data gained from the interview. Finally, they had medium and low English proficiency as classified by their previous grades and their pronunciation test scores.

\subsection{Variables}

Independent variables: The two methods of instruction that were the computer-based 
pronunciation package and the conventional face-to-face instruction on English pronunciation.

Dependent variable: The students' learning achievement on English pronunciation and attitudes towards learning via the computer-based pronunciation package.

\subsection{Research Instruments}

The instruments used in this research are:

1. The 3 units of lesson plans for conventional face-to-face instruction.

2. The computer-based pronunciation package created by the researcher.

3. The English pronunciation test which was used as a pre-test and post-test to contrast the progress of students' learning achievement on English pronunciation.

4. The questionnaire to study students' attitudes towards learning English pronunciation with computer-based pronunciation package, constructed by using the Likert method.

\subsection{Validity and Reliability}

\subsubsection{Pretest and posttest of pronunciation competency}

Three language specialists were consulted to check the content and validity of this test. The revised test was then tried out with 35 second-year students to check the level of difficulty of test items (p) and the discrimination index (D). The test items with value of level of difficulty between 0.20 to 0.80 and the discrimination index higher than 0.20 were selected. Then, the test scores were calculated to check for reliability using the Kuder-Richardson Formula 20 $\left(\mathrm{KR}_{20}\right)$. The value of this reliability test was 0.78 .

\subsubsection{Computer-based pronunciation package}

The content of initial e-learning lessons was approved and analyzed by 3 language specialists in English teaching. After approval, the lessons were revised and improved accordingly. The storyboard was evaluated and approved by 3 media experts. Before first administering the experiment with students, feedback from 3 media experts was used to improve the computer-based pronunciation package. Then, the 3 lessons of consonant sound, vowel sound, stress and intonation were programmed and the package was tested.

\subsubsection{Questionnaire}

Three language specialists were consulted to check the congruence between the questionnaire items. The value of Index of Congruence (IOC) was between 0.6-1.0. The students were required to rate the statements on a five-point scale from "very low" to "very high". The initial questionnaire was then tested and improved to make it more comprehensive, reliable and valid for collecting data. The Cronbach's Alpha value $(\alpha)$ of this questionnaire was 0.80 .

\subsection{Research Procedure}

1. The a computer-based pronunciation package learning procedures and learning objectives 
were described to the students step-by-step.

2. The students were divided into two groups: the control group which would study by conventional face-to-face instruction and the experimental group which would study with the computer-based pronunciation package only.

3. The students in the sample groups took the pre-test first.

4. The control and experimental groups learned with the teacher and the computer-based pronunciation package respectively.

5. When finishing the course, two groups were assigned to do a post-test.

6. Pre-test and post-test scores of each group were obtained to evaluate the learning progress and to compare post-test scores of the control group and the experimental group to determine the effectiveness of computer-based pronunciation package by using t-test at 0.05 levels.

7. After completing the course, the experimental group was assigned to respond to a questionnaire regarding attitudes towards usage of computer-based pronunciation package.

8. Students' opinions obtained in step 7 were analyzed statistically in order to obtain a quantitative assessment of their attitude to the computer-based package.

\subsection{Data Analysis}

The data obtained from this method of teaching in the study was analysed and interpreted through quantitative analysis. Quantitative data includes the data obtained from the pre-test, the post-test and the questionnaire. The t-test was used to compare the pronunciation competency of the experimental group. The computer software program, SPSS, was used to analyse the data. The data from the Likert's scale was calculated for the arithmetic means $(X)$. These means revealed the students' opinions towards learning via computer-based pronunciation package.

\section{Findings}

\subsection{Evaluation of Effectiveness of the Computer-Based Pronunciation Package}

To evaluate the effectiveness of English pronunciation lessons via computer-based package, three steps of try-out in the developmental testing process were conducted. After each of these steps of try-out, the content in each lesson was revised and improved in order to ensure the design was appropriate for the students.

The efficiency value of $80 / 80$ of computer-based package was defined by the researcher. The resultant efficiency value of the three try-outs: one-to-one testing (1:1), small group testing $(1: 10)$ and field group testing (1:100) was as described below: 
Table 2. Resultant efficiency value of the computer-based package try-outs

\begin{tabular}{|c|c|c|}
\hline Try-out Group & $\begin{array}{c}\text { Efficiency of Process } \\
\text { (E1) } \\
\text { (Defined efficiency value } \\
\text { is } 80)\end{array}$ & $\begin{array}{l}\text { Efficiency of Product } \\
\text { (E2) } \\
\text { (Defined efficiency value is } \\
80)\end{array}$ \\
\hline One to one testing & 73.33 & 74.44 \\
\hline Small group testing & 77.40 & 79.62 \\
\hline Field group testing & 81.88 & 82.66 \\
\hline
\end{tabular}

Table 2 above showed that the value of efficiency of E1/E2 for one to one testing was 73.33/74.44. For small group testing, it was 77.40/79.62. Based on the results of both tests, it could be inferred that this computer-based package must be improved prior to further implementation. After it was revised and improved, it was tried out with 30 students who were in different groups from the first and second testing stages. The result revealed that the value of efficiency of E1/E2 as 81.88/82.66. To summarize, this computer-based package is developed according to the standard criteria 80/80 defined. This corresponded to the first hypothesis of this study.

\subsection{Evaluation of Comparison of English Pronunciation Tests between Control Group and} Experimental Group

To compare the English pronunciation ability of both groups, an independent-samples t-test is used to determine whether the mean difference between the post-tests of both groups is statistically significant. The findings are shown in the table 3 below

Table 3. Result of comparison between control group and experimental group

\begin{tabular}{|c|c|c|c|c|c|}
\hline Group & $\mathrm{n}$ & $\overline{\mathrm{X}}$ & $S D$ & $\mathrm{t}$ & $\begin{array}{c}\text { Sig. } \\
\text { (2-tailed) }\end{array}$ \\
\hline Control group & 37 & 14.14 & 1.960 & \multirow{2}{*}{-7.01} & .000 \\
\hline Experimental group & 35 & 17.43 & 2.019 & \\
\hline
\end{tabular}

$\mathrm{P}<.05$

Table 3 above showed the comparative result of the pronunciation ability test between students taught by computer-based package and those who studied with the conventional face-to-face instruction. The average mean scores of the control group and the experimental group are 14.14 and 17.43 respectively. The standard deviation of the control group and the experimental group are 1.96 and 2.01 respectively. According to the result of the t-test which was -7.01, it can be concluded that the learning achievement of the experimental group is higher than the control group at a significant level of 0.05 . This corresponded to the second hypothesis of this study. 


\subsection{Evaluation of Students' Attitudes toward s Computer-based Pronunciation Package}

The questionnaire for this part of the study was constructed by the researcher in order to gather information concerning students' feelings, opinions, comments and recommendations on strengths and weaknesses of learning with this computer-based pronunciation package. 35 students were asked to respond to the questionnaire. The questionnaire includes two parts. The first part consists of Likert scale questions, and the second part consists of open-ended questions.

For the first part, the data obtained from the 5-point rating scale were used to calculate the arithmetic means $(\bar{X})$. It has been found that the mean score ranges between 3.54 to 4.37 , which is in between average to high levels. The highest mean score (4.37) is the item "User's manual clearly describes how to use computer-based package." The lowest mean score (3.37) is the item "Specified time for learning with computer-based lesson is appropriate." The average mean score overall of this dimension is 4.00, which shows that students had very good attitudes towards learning English pronunciation via computer-based pronunciation package. In conclusion, the average mean score overall of this dimension is 4.00 , which is in the high level. This corresponded to the third hypothesis of this study.

\section{Discussion and Conclusion}

The findings of this study revealed that the use of computer-based pronunciation package to develop pronunciation skill of first-year students seemed to be effective, as indicated by the post-test score which was significantly higher than the pre-test score. The findings of this experiment concur with several related studies. Suwanbenjakul (2002) investigated the use of web-based instruction on the element of grammar known as relative clauses. The participants in the experiment were 80 students studying at grade 5 elementary school. The result revealed that the instruction achieved an efficiency level of $83.33 / 80.13$. It was also found that students who learnt with WBI possessed a good attitude toward this method. In addition, the study on courseware development on research methods in educational technology through web-based instructional systems conducted by Jirasathidpornpong (2004) also revealed that the efficiency of E1/E2 was 80/80. Tsai and Jenks' study (2009 as cited in Chien, 2011) investigated effect of a Teacher Guided Multimedia CD-ROM program as a supplement in teaching vocabulary acquisition to EFL students. Students from two intact classes were assigned to the control and the experimental groups for four weeks. The control group received two hours of traditional instruction only. The same instructor taught both groups lessons of identical content. The results showed that the experimental group achieved better English vocabulary acquisition than the traditional didactic instruction group.

Analysis of the students' responses from the questionnaire revealed that they were more interested in learning English if the teacher used computer-based pronunciation package as a teaching material. They explained that the computer-based pronunciation package attracted them to use it for a long time due to colorful pictures and sounds of native speakers. The students with high ability showed that they had more motivation to improve their pronunciation while the students with poor pronunciation just tried to finish their lesson. 
Overall, students agreed that the computer-based pronunciation package were useful in learning English pronunciation. The finding of this study was in line with the study conducted by Brett (1996 as cited in Chiu, 2003) who conducted a study on the feasibility of applying a multimedia learning provision into a university language curriculum. The result revealed that positive attitudes of learners toward learning via the program. The study concluded that that multimedia has potential to enhance effective language learning and serves a beneficial role in the curriculum. Multimedia could also motivate students who perceived themselves as having low language competencies. Students' perception is another important aspect to consider when using computer-assisted program in the classroom. According to Burrus (2009) and Salaberry (2001), although the findings from studies can be limited and not always applicable to every learning context, several times these studies were conducted without strong reliability and validity or with problems arising from data collection, scoring, and analysis and difficulty in long-term studies. However, there is substantial data that shows overall student positive perceptions toward learning via CALL (Felix, 2005 and Son, 2007).

\section{Teaching Implications and Recommendations}

Moreover, this study focused on students at the beginning level of proficiency in learning English pronunciation. Further research should be conducted with more advanced students as it would be important to provide a full picture of Thai university students' needs in computer assisted instruction. Besides, the students suggested that more games or drills would improve computer-based pronunciation package because they would arouse the interest of the students and be motivating.

There were more females than males in this study, and it is suggested that comparing the different requirements and learning behavior of males and females would be advantages. In addition, research into computer assisted instruction for the use of students with different learning styles would be beneficial.

According to the students' feedback, there was a requirement for the provision of Thai translation in details in some parts of the lessons in the computer-based pronunciation package. The amount and level of this translation will depend on the proficiency of the students.

\section{References}

Burrus, J. (2009). Adult ESL student perceptions on computer-assisted language learning. Master's thesis, University of Nevada Las Vegas.

Chien, Y. (2011). Effects of computer-assisted language learning instruction on the acquisition of passive grammatical forms by post-secondary English as a Second Language Students. Doctoral dissertation, University of Central Florida Orlando, Florida.

Chiu, Mei-Wen (2003). Computer-assisted language learning: Attitudes of Taiwanese college students. Doctoral dissertation, The University of West Florida.

Chute, A. G., Thompson, M. M., \& Hancock, B. W. (1999). The McGraw-Hill Handbook of 
distance learning. New York: McGraw-Hill.

Erricolo, D., \& Matthes, R. A. (1999). Web-based instruction in engineering. IEEE Antennas and Propagation Magazine, 41(6), 113-117.

Felix, U. (2005). Analysing recent call effectiveness research--towards a common agenda. Computer Assisted Language Learning, 18, http://dx.doi.org/10.1080/09588220500132274

Gorjian, B., \& Saffarian, R. (2012). The effect of multisensory techniques on reading comprehension among pre-intermediate EFL learners: The case of gender. Advances in Asian Social Science, 1(2), 192-196.

Hazari, S. I., \& Schnorr, D. (1999). Implementation and outcomes of interactive web course module. Journal of Computing in Teacher Education, 15(3), 8-16.

Imamesup, A. (2011). The study of the effectiveness of audioarticulation model in improving Thai learners' pronunciation of fricatives sounds. Master's thesis, Srinakharinwirot University.

Jirasathidpornpong, T. (2004). The development of courseware on research methods in educational technology through web-based instructional systems. Unpublished master's thesis, Kasetsart University, Bangkok.

Kelly, G. (2004). How To Teach Pronunciation. Harlow: Longman.

Khamkhien, A. (2010). Thai Learners' English Pronunciation Competence: Lesson Learned from Word Stress Assignment. Journal of Language Teaching and Research, 1(6), 757-764. http://dx.doi.org/10.4304/j1tr.1.6.757-764

Lin, H., et al. (1995). Teaching pronunciation in the learner-centered classroom. ERIC Document Reproduction Service No. ED393292.

Lu, D. (2002). Phonetic symbols: A necessary stepping stone for ESL learners. English Teaching Forum, 40(4), 36-39.

Mikuláštíková, J. (2012). Teaching Pronunciation at Secondary Level. Master's thesis, Univerzita Palackého Olomouci.

Morley, J. (1998). Trippingly on the tongue: Putting serious speech/pronunciation instruction back in the TESOL equation. ESL Magazine, issue January/ February, 20-23. http://dx.doi.org/10.1017/cbo9780511755095.007

Romwapee, W. (2013). Junior High School Students' English Pronunciation Development through Reading-aloud Dominoes. Retrieved July 12, 2015 from: http://www.huso.kku.ac.th/thai/HSGS/SGR/SGR_01_P1_02.pdf

Salaberry, R. (2000). The use of technology for second language learning and teaching: A retrospective. Modern Language Journal, 85(1), 35-56. http://dx.doi.org/10.1111/0026-7902.00096 


\section{Macrothink

Salomon, G. (1988). Artificial intelligence in reverse: Computer tools that turn cognitive. Journal of Educational Computing Research, 4, 123-134.

Spiro R. J., \& Jehng, J. C. (1990). Cognitive flexibility and hypertext: Theory and technology for the nonlinear and multidimensional traversal of complex subject matter. In D. Nix \& R. J. Spiro (Eds.), Cognition, education, and multimedia: Exploring ideas in high technology. Hillsdale, NJ: Lawrence Erlbaum.

Son, J. (2007). Learner experiences in web-based language learning. Computer Assisted Language Learning, 20(1), 21-36. http://dx.doi.org/10.1080/09588220601118495

Suwanbenjakul, B. (2002). The development of web-based instruction on relative clauses for the grade 6 students at Kham-Sakaesaeng School, Nakhon Ratchasima. Unpublished master's thesis, Suranaree University of Technology, Nakhon Ratchasima.

Tessmer, M. (1993). Planning and conducting formative evaluation. London: Kogan Page. http://dx.doi.org/10.1177/109821409601700309

Varasarin, P. (2007). An action research study of pronunciation training, language learning strategies and speaking confidence. Doctoral dissertation, Victoria University.

Wei, Y. \& Zhou, Y. (2002). Insights into English pronunciation problems of Thai students. ERIC Document Reproduction Service No. ED476746.

Yiğit, A. M. (2013). Teachers' attitudes towards the "Dyned" in primary education in Turkey. Journal of Educational and Instructional Studies in the World, 3(3), 56-65.

Yong, C. (2004). How can I improve the pronunciation and intonation of the first year English majors to meet the demand of the new English curriculum? Report submitted to China's Experimental centre for Educational action research in foreign languages teaching, June 25th, 2004, Guyuan, Ningxia. 